American Journal of Environmental Sciences 5 (3): 451-454, 2009

ISSN 1553-345X

(C) 2009 Science Publications

\title{
Desalination leading to Salinity Variations in Kuwait Marine Waters
}

\author{
Ahmad E. Al-Dousari \\ Department of Environmental Sciences, Kuwait Institute for Scientific Research, \\ P.O. Box 24885, Safat 13109, Kuwait
}

\begin{abstract}
Problem statements: The salinity of seawater is a critical issue for desalination process. Approach: The salinity changes in the coastal waters of Kuwait due to large scale power and desalination activity were evaluated. Results: Systematic sampling campaigns were planned to cover the uptake and outfall of the desalination plant spreading evenly the sampling points to cover the freshwater input zone of Arabian Gulf in north. The salinity observations are critical both for the desalination process and for integrity of the marine environment, which is critical in case of Kuwait. Conclusion/Recommendations: The results showed compliance of Kuwait EPA salinity standard in the area with a difference of around $4 \mathrm{ppt}$ salinity increase at outfall compared to uptake zone.
\end{abstract}

Key words: Power and desalination plant, Kuwait, environmental impact assessment

\section{INTRODUCTION}

The fresh water resource in Middle East is scarce commodity, occurring as shallow aquifers and freshwater lenses. Being an arid and hyper arid region with unreliable precipitations, recharge to these shallow water sources is quite limited. To over come the water scarcity issue non conventional sources of water are being used including treated waste water, brackish water and desalination of sea water.

Desalination is the most widely used practice to meet the fresh water demand of the Middle Eastern countries and North Africa. The process of desalination in Arabian Gulf has its own legitimate concerns with most of the northern region having $<30 \mathrm{~m}$ depth. The shallower depths on western margin have huge installed capacities of desalination and environmental concern related to chemical discharges, salinity, discharge temperatures and other water quality issues, which can impair the integrity of the marine environment and finally the desalination activity itself.

This study reviews the changing salinity consequent to desalination activity off the Kuwaiti coast. The water intake of $\mathrm{P}$ and $\mathrm{D}$ plant is very critical for the operation of the plant itself and the environment since, initial loss of biota occur in the intake zone due to impingement and entrainment effects and chlorination process. The chlorination is done to combat biofouling in the uptake zone. The desalinated plant separates the water into two streams the desalinated water and the brine ${ }^{[3]}$. The brine is rejected into the sea. The characteristic of the rejected brine is dependent on the quality of feed water used, desalination technique, percent recovery and chemical additives used for the process. Most of the desalination plants in Arabian Gulf are located on the coast and their brine is discharged directly into the near shore. There is scarce information available on impacts of these brines on biota in Arabian Gulf. The most common, inexpensive and least hazardous method of brine disposal is ocean discharge. In this the brine due to higher density sinks to the bottom and gets mixed with oceanic water with similar physico-chemical characteristic leading to potentially safe environment. However this is of concern in areas like Northern Arabian Gulf where the bathymetry are extremely shallow. In such cases the spatial distribution of brine becomes a matter of concern and hydrodynamics and sea surface temperature and salinity will give a clue to how much spatial extent is affected during different tidal conditions. In a typical thermal desalination process about $4.5 \mathrm{~m}^{3}$ of seawater is used to produce $1 \mathrm{~m}^{3}$ of desalinated water.

The impact of the outfall discharges can be physical impact due to high temperature discharge, chemical impacts due to chlorination, descaling and antifoaming and the biological impacts due to increased oxygen demand because of induced organics and otherwise lower DO of the heated brine.

The environmental impact of brine discharge in open sea poses a significant concern even though the salt discharged is similar to that in the open sea and in most of the cases the brine is blended with cooling water before it is released to the sea. This blending of brine with cooling water lowers the salinity of brine to not more than three times the open sea. Also the heavier discharge sinks to the bottom due to its density. The huge 
volume in open sea compared to the discharged quantity and quick circulation mitigates the issue naturally to considerable extent ${ }^{[5]}$.

But this effect is extremely important in semienclosed areas with very limited fresh water input, shallow bathymetry and weak circulation, like the situation in Northern Arabian Gulf. Occasional variations in salinity and limited temporal exposures are usually accommodated by the native species which inhabit the area. However continuous exposure to increased salinity might not be adaptable for many native species, leading to extension of some and reduced biodiversity in general. The issue of hyper saline conditions is critical for fragile and sensitive ecosystems like the one in study area. Therefore it is very important to look into the efficiency and type of desalination, the percentage recovery of desalination varies from $20-65 \%$ giving rise to salinity between 125-300\% of the background salinity.

Recent studies in Arabian Gulf ${ }^{[4]}$ modeled the change in salinity due to desalination process considering a peak salinity of $40 \mathrm{ppt}$ suggested an increase of salinity of the order of $0.06 \mathrm{ppt}$ due to Al Jubail desalination plant in Saudi Arabia. The observation was based on simplistic modeled assumptions. The actual spatiotemporal salinity variations in Northern Arabian Gulf are much more complex and higher in magnitude then reported in the regional studies ${ }^{[5]}$. However the extent of the variation is often spatially limited, never the less it is a huge concern.
This manuscript focuses on changing salinity off the northern Arabian Gulf that might be crucial for sustainable marine environment.

\section{MATERIALS AND METHODS}

\section{Environmental Impacts of increased salinity from the} outfall: The environmental impact of brine discharge in open sea is significant but the concerns are not alarming since the salt discharged is similar to that in the open sea and in most of the cases the brine is blended with cooling water before it is released to the sea that lowers the salinity of brine to not more than three times the open sea. Also the heavier discharge sinks to the bottom due to its density. The huge volume in open sea compared to the discharged quantity and quick circulation mitigates the issue naturally to considerable extent. But this effect will be extremely important in semi-enclosed areas with shallow bathymetry and weak circulation, like that in northern Arabian Gulf. The higher salinity buildup may significantly affect the marine biodiversity ${ }^{[2]}$. Therefore it is very important to look into the efficiency and type of desalination, the percentage recovery of desalination varies from $20-65 \%$ giving rise to salinity between 125 $300 \%$ of the background salinity ${ }^{[1]}$.

The hydrolab instrument was used to measure salinity during field campaigns on 6th and 7th February and 8th March, 2008 in northern Kuwaiti territorial waters and on 25th May and 1st June 2008 in Southern Kuwaiti waters (Fig. 1 and 2).

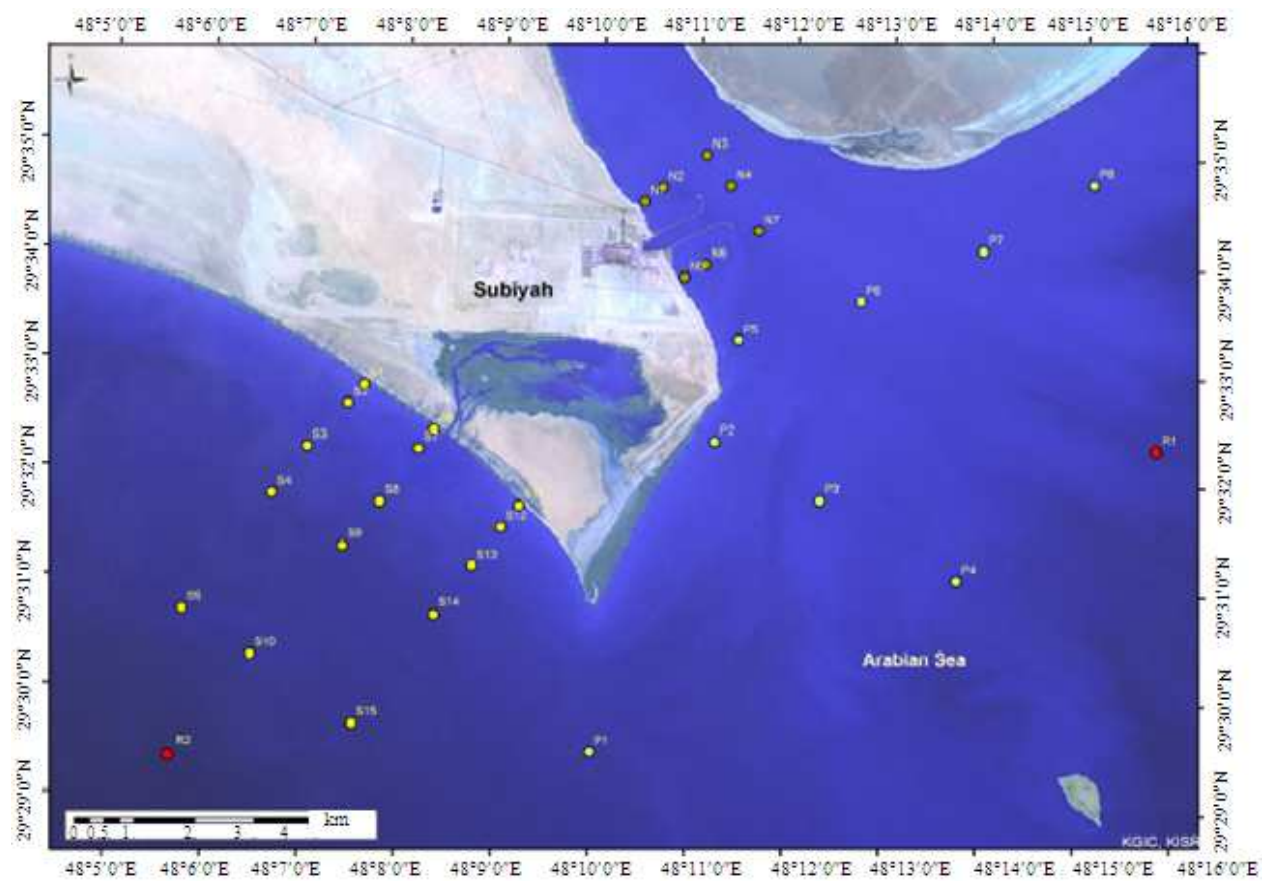

Fig. 1: Sampling stations in the Kuwait marine waters near Subiya power and desalination plant 
Am. J. Environ. Sci., 5 (3): 451-454, 2009

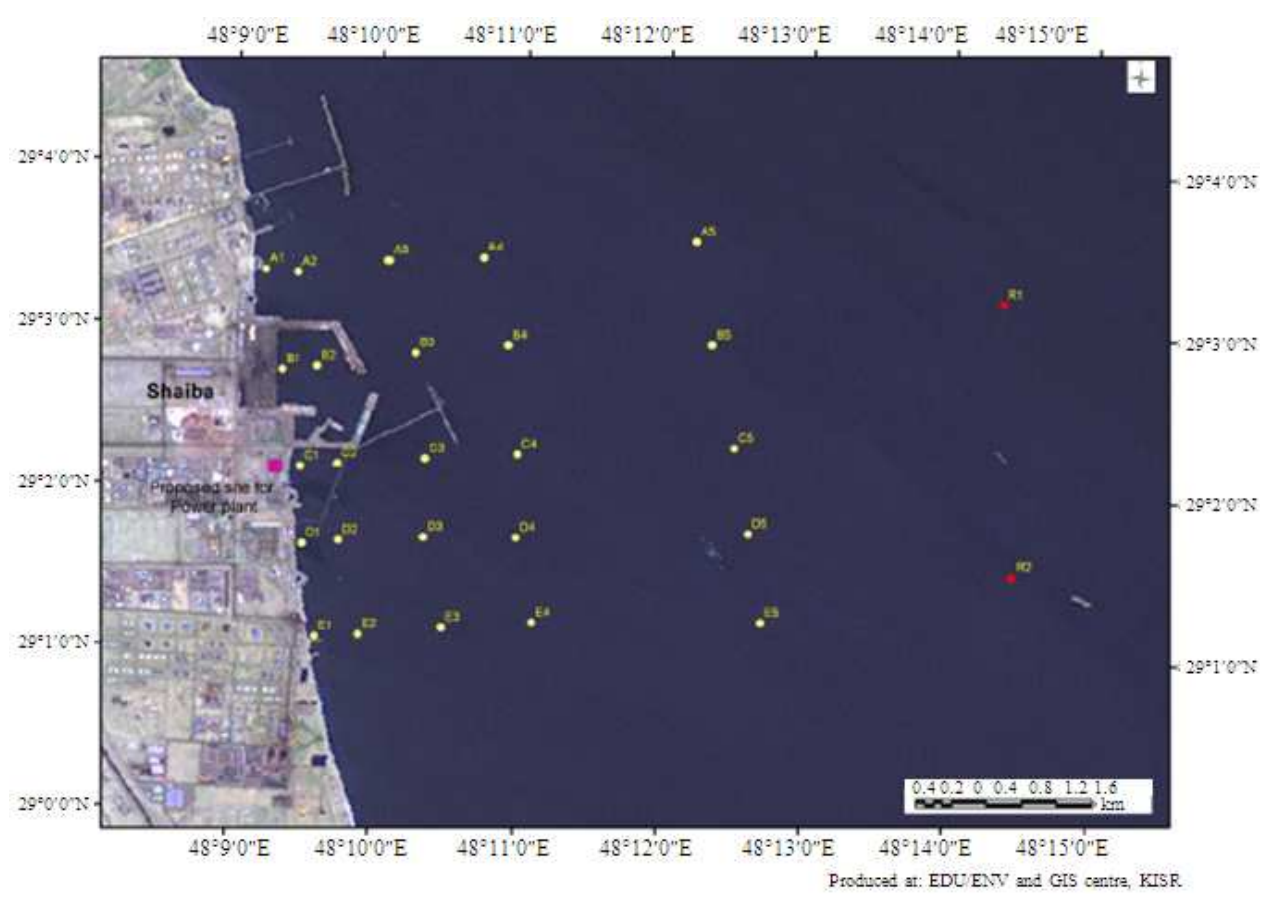

Fig. 2: Sampling stations in the Kuwait marine waters near Shuaiba Power and Desalination plant

\section{RESULTS}

The water samples from 26 sampling points in northern area and 27 locations in south show a salinity values less than $42 \mathrm{ppt}$ which is the maximum salinity value set forth by Kuwait Environmental Protection Authority. The only fresh water input to the northern Arabian Gulf comes through the Third River and the Shaat Al Arab. The fresh water input to northern part reduces the salinity to $\sim 36 \mathrm{ppt}$ where as it is above 38 ppt in southern areas. The spatial analyses of the salinity area highlights the higher salinity values to a tune of over $40 \mathrm{ppt}$ at the outfall of power and desalination plant. This 4 ppt increase in salinity is a drastic change within a small spatial coverage. The values are not posing any serious environmental concern as of now, and there is a room for further development of the $\mathrm{P}$ and $\mathrm{D}$ facility in the area. However the concern become a more serious over time with decreasing river input to the northern waters and coastal evolution at the project sites the situation may turn adversely.

\section{DISCUSSION}

The salinity variations that have been observed suggest an increase of $4 \mathrm{ppt}$ salinity at the outfall of the power and desalination facility compared to the ambient salinity concentration. However in this specific case of Subiya power plant there are no apparent threats due to salinity exceedence, but a close watch is required at salinity trends in Shuaiba area. The salinity trends at the sampling site were higher but withing the permissible limits of marine water quality set forth by Kuwait Environment Public Authority.

The Kuwait EPA has set 42 ppt as upper limit for salinity in marine waters, which is considered safe for the biota and ecological balance in the marine environment ${ }^{[6]}$. Review of the historical data highlights an interesting fact that there were no incidence of salinity exceedence till 2002, it was only during three month in summer of 2003 when the salinity crossed the $42 \mathrm{ppt}$ threshold but remained less then $43 \mathrm{ppt}$ on all the occasions ${ }^{[5]}$. In order to further explore the salinity variation within the area fortnight salinity measurements were done between 1st January 2007 to 31st March 2009 at an observation station in open waters South of $\mathrm{Az}$ Zour power and desalination plant ${ }^{[5]}$. Incremental seasonal salinity is observed in both summer and winter months usually over the $42 \mathrm{ppt}$ maximum salinity limit set forth by Kuwait Environmental Public Authority in south Kuwait, suggesting the influence of fresh water discharge minimizes the salinity exceedence incidence in north Kuwait, which the issue remains serious in south. This also suggest a weaker circulation in southern Kuwait territorial water. 
The observations in 2007-2009 shows extremely higher salinity peaking around $50 \mathrm{ppt}^{[6]}$. This can partly be attributed to increased desalination capacity due to expansion at Az Zour Power and Desalination Plant in 2005. But the groundtruth carried out between Jan 2007-March 2009 shows exceedence of salinity during most part of the year.

\section{CONCLUSION}

The long term strategy of $\mathrm{P}$ and $\mathrm{D}$ plant operation should consider redesigning the wastewater outfall to deeper waters in the areas where the rivers drain into northern part of Arabian Gulf. The other scenario that might be explored is mixing this brine with two to three part of treated wastewater before disposal in offshore. The option of utilization of treated wastewater with brine during discharge will be a good mitigation measure in long term. Several studies in the region suggest that thou the salinity issue is serious but may not pose a serious danger to the biota and ecosystem health in particular in NAG, due to adaptability of higher temperatures and salinity in the region.

Another aspect of salinity that remains outstanding is the fact that the aquifers in northern part are extremely saline and any leak from them may increase salinity considerably. To conclude the power and desalination plant remains the only means of reliable water supply in the country. The difference in brines due to different process may still give some more meaningful information about the salinity trends, probablt Reverse osmosis may produce the brine with lower salinity but will be costlier for large scale implementation.

\section{REFERENCES}

1. Khordagui, H., 2002. Environmental Impacts of Power-Desalination on Gulf Marine Ecosystem. In: The Gulf Ecosystem: Health and Sustainability, Khan, N.Y., M. Munawar and A. Price (Eds.). Backhuys Publisher, Leiden, ISBN: 9057821060, pp: 173-191.

2. Lattemann Sabine and Höpner Thomas, 2008. Environmental impact and impact assessment of seawater desalination. Desalination, 220: 1-15. http://cat.inist.fr/?aModele $=$ afficheN\&cpsidt $=2029$ 5188

3. Mandil, A.M., 1991. Desalination and environment. Proceedings of the 3rd International Symposium on Industry and Environment in Developing World, ISIEDW, May 1991, Alexendria, Egypt.

4. Purnama, A., H.H. Al Barwani and R. Smith, 2005. Calculating the environmental cost of seawater desalination in the Arabian marginal seas. Desalination, $\quad$ 185: 79-86. http://cat.inist.fr/?aModele $=$ afficheN\&cpsidt=1734 8922

5. Saif Ud Din, D. Al Shamroukh, A. Al Khabbaz and A. Al Yagoub, 2009. Assessment and Monitoring of Water Quality for the Khairan Pearl City Project. Technical Report, Kuwait Institute for Scientific Research, No. 9512, pp: 31.

6. Saif Ud Din, A. Al Dousari, A.N. Al Ghadban, D. Al Shmaroukh and M. Al Murad, 2009. Localized Hyper Saline Waters in Arabian Gulf from Desalination activity-An example from South Kuwait. Desalination (Under Review). 